\title{
FINAL OOCYTE MATURATION IN NORMORESPONDER PATIENTS UNDERGOING INTRACYTOPLASMIC SPERM INJECTION: GNRH AGONIST VS. DUAL VS. RCHG
}

Yavuz Emre şÜKÜR', Fatma Ceylan ILHAN², Murat SÖNMEZER', Bülent BERKER', Cem ATABEKOĞLU1, Batuhan ÖZMEN'

${ }_{1}$ Ankara University School of Medicine, Department of Obstetrics and Gynecology, Ankara, TURKEY

${ }^{2}$ Yenimahalle Training and Research Hospital, Department of Obstetrics and Gynecology, Ankara, TURKEY
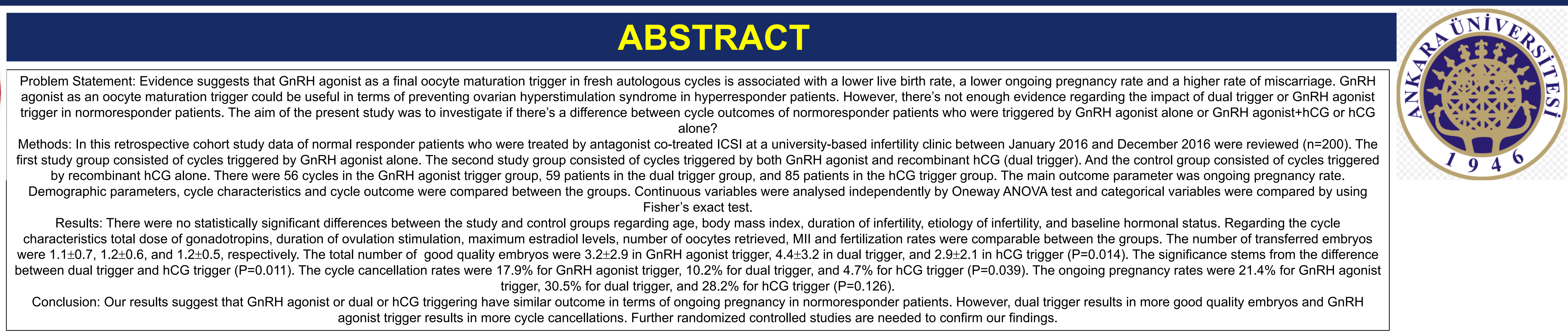

\section{BACKGROUND}

While mature oocytes are necessary for oocyte retrieval and fertilization, final oocyte maturation is the key step in in vitro fertilization (IVF)/intracytoplasmic sperm injection (ICSI) cycles. Human chorionic gonadotropin (hCG) has been used to trigger final follicle maturation, which is a prerequisite for oocyte fertilization, for many years in IVF/ICSI cycles and promoted the pregnancy rates. However, hCG administration for final oocyte maturation resulted in supra-physiologically elevated steroid levels in the luteal phase due to its long half-life. Hence, ovarian hyperstimulation syndrome (OHSS) risk is increased (1).

Recently, gonadotropin releasing hormone $(\mathrm{GnRH})$ agonists have been introduced for final oocyte maturation in $\mathrm{GnRH}$ antagonist down-regulated cycles $(2,3)$. It has been documented that $\mathrm{GnRH}$ agonists induce endogenous $\mathrm{LH}$ and FSH surges similar to natural mid-cycle LH surge with a shorter effect duration compared to exogenous hCG which may help to reduce the risk of OHSS (4).

Evidence suggests that $\mathrm{GnRH}$ agonist as a final oocyte maturation trigger in fresh autologous cycles is associated with a lower live birth rate, a lower ongoing pregnancy rate and a higher rate of miscarriage. GnRH agonist as an oocyte maturation trigger could be useful in terms of preventing OHSS in hyperresponder patients. However, there's not enough evidence regarding the impact of dual trigger or GnRH agonist trigger in normoresponder patients.

The aim of the present study was to investigate if there's a difference between cycle outcomes of normoresponder patients who were triggered by GnRH agonist alone or $\mathrm{GnRH}$ agonist $+\mathrm{hCG}$ or $\mathrm{hCG}$ alone?

\section{METHODS}

In this retrospective cohort study data of normal responder patients who were treated by antagonist co-treated ICSI at a university-based infertility clinic between January 2016 and December 2016 were reviewed $(n=200)$. The first study group consisted of cycles triggered by $\mathrm{GnRH}$ agonist alone. The second study group consisted of cycles triggered by both GnRH agonist and recombinant hCG (dual trigger). And the control group consisted of cycles triggered by recombinant hCG alone. There were 56 cycles in the GnRH agonist trigger group, 59 patients in the dual trigger group, and 85 patients in the hCG trigger group.

The inclusion criteria were female age 18-40 years, baseline FSH level 3-15 IU/l, baseline $\mathrm{LH}$ level $>3 \mathrm{IU} / \mathrm{I}$, a starting dose of gonadotropin stimulation with a dose of $150 \mathrm{IU} /$ day. The exclusion criteria were secondary infertility, body mass index (BMI) $>30 \mathrm{~kg} / \mathrm{m}^{2}$, poor response to ovarian stimulation, presence of any untreated thyroid dysfunction/hyperprolactinemia, and/or presence of uterine abnormality. For eligible participants, all data regarding COS and clinical outcomes were extracted from the database, and the patients were divided into three groups according to final oocyte trigger

An injection of $0.2 \mathrm{mg}$ triptorelin acetate (Gonapeptyl $0.1 \mathrm{mg}$, Ferring, Istanbul, Turkey) or $1 \mathrm{mg}$ (20 units in a tuberculin syringe of $5 \mathrm{mg} / \mathrm{ml}$ injectable solution) leuprolide acetate (Lucrin $5 \mathrm{mg}$, Abbott, Istanbul, Turkey) was administered for final oocyte maturation in the first group. However, in the second group in addition to one of these GnRH agonists 1500 IU hCG was administered. In the last group, $10000 \mathrm{IU}$ hCG (Pregnyl; MSD, Oss, Holland) was administered for final oocyte triggering. Ovarian stimulation was carried out with recombinant FSH (Gonal-F, Merck-Serono, Istanbul, Turkey) beginning from the second day of the menstrual cycle with a fixed starting dose of $150 \mathrm{IU} /$ day when the antral follicle count was $>12$ per ovary. Dose adjustment was performed individually according to ovarian response. The GnRH antagonist (Cetrotide, Merck-Serono, Istanbul, Turkey) was introduced $(0.25 \mathrm{mg} /$ day $)$ on the sixth day (fixed antagonist protocol) and continued throughout ovarian stimulation. When at least three follicles were $\geq 18 \mathrm{~mm}$, final oocyte triggering was performed. Transvaginal ultrasonography guided oocyte pick-up (OPU) was performed 35-36 hours after final oocyte trigger. Embryo transfer was performed on the $3^{\text {rd }}$ day of OPU. A maximum of two embryos were transferred under ultrasound guidance due to national embryo transfer regulations. Vaginal micronized progesterone $90 \mathrm{mg} /$ day (Crinone $8 \%$ gel; Merck-Serono, Istanbul, Turkey) was administered to all patients for LPS starting OPU day until the pregnancy test, and women with a positive result continued progesterone supplementation until 10 weeks of gestation.

The main outcome parameter was ongoing pregnancy rate. Demographic parameters, cycle characteristics and cycle outcome were compared between the groups. Continuous variables were analysed independently by Oneway ANOVA test and categorical variables were compared by using Fisher's exact test.

\section{RESULTS}

There were no statistically significant differences between the study and contro groups regarding age, body mass index, duration of infertility, etiology of infertility, and baseline hormonal status (Table 1). Regarding the cycle characteristics total dose of gonadotropins, duration of ovulation stimulation, maximum estradiol levels, number of oocytes retrieved, MII and fertilization rates were comparable between the groups. The number of transferred embryos were $1.1 \pm 0.7,1.2 \pm 0.6$, and $1.2 \pm 0.5$, respectively. The total number of good quality embryos were $3.2 \pm 2.9$ in $\mathrm{GnRH}$ agonist trigger, $4.4 \pm 3.2$ in dual trigger, and $2.9 \pm 2.1$ in $\mathrm{hCG}$ trigger $(P=0.014)$. The significance stems from the difference between dual trigger and hCG trigger $(P=0.011)$. The cycle cancellation rates were $17.9 \%$ for $\mathrm{GnRH}$ agonist trigger, $10.2 \%$ for dual trigger, and $4.7 \%$ for $\mathrm{hCG}$ trigger $(\mathrm{P}=0.039)$. The ongoing pregnancy rates were $21.4 \%$ for $\mathrm{GnRH}$ agonist trigger, $30.5 \%$ for dual trigger, and $28.2 \%$ for $\mathrm{hCG}$ trigger $(\mathrm{P}=0.126)$ (Table 2).

\begin{tabular}{|c|c|c|c|c|}
\hline Table 1 & $\begin{array}{c}\text { GnRH agonist } \\
\quad \mathrm{N}=56\end{array}$ & $\begin{array}{l}\text { Dual } \\
N=59\end{array}$ & $\begin{array}{l}\text { rHCG } \\
n=85\end{array}$ & $\mathbf{P}$ \\
\hline Age, years & $30.6 \pm 4.7$ & $31.4 \pm 4.2$ & $32.1 \pm 4.5$ & 0.188 \\
\hline $\mathrm{BMI}, \mathrm{kg} / \mathrm{m}^{2}$ & $23.5 \pm 4.2$ & $24.8 \pm 3.5$ & $24.9 \pm 3.7$ & 0.166 \\
\hline Bazal $E_{2}, \mathrm{pg} / \mathrm{ml}$ & $42.2 \pm 21.4$ & $53.4 \pm 38.0$ & $48.7 \pm 20.2$ & 0.092 \\
\hline $\mathrm{FSH}, \mathrm{IU} / \mathrm{L}$ & $8.2 \pm 4.4$ & $7.5 \pm 4.5$ & $8.2 \pm 3.7$ & 0.571 \\
\hline$L H, I U / L$ & $4.7 \pm 2.7$ & $4.4 \pm 2.3$ & $4.4 \pm 2.1$ & 0.761 \\
\hline Duration of infertility, years & $6.4 \pm 3.5$ & $6.1 \pm 2.8$ & $5.8 \pm 2.4$ & 0.508 \\
\hline Etiology of infertility & & & & 0.062 \\
\hline Female & 9 (\%16.1) & $15(\% 25.4)$ & $20(\% 23.5)$ & \\
\hline Male & $31(\% 55.4)$ & $17(\% 28.8)$ & $38(\% 44.7)$ & \\
\hline Unexplained & $16(\% 28.6)$ & $27(\% 45.8)$ & $27(\% 31.8)$ & \\
\hline Table 2 & $\begin{array}{c}\text { GnRH agonist } \\
\quad \mathrm{N}=56\end{array}$ & $\begin{array}{c}\text { Dual } \\
\mathrm{N}=59\end{array}$ & $\begin{array}{l}\mathrm{rHCG} \\
\mathrm{n}=85\end{array}$ & $\mathbf{P}$ \\
\hline Total dose of gonadotropins,IU & $2442 \pm 975$ & $2390 \pm 1049$ & $2725 \pm 932$ & 0.086 \\
\hline Duration of stimulation, days & $9.4 \pm 1.3$ & $9.5 \pm 2.4$ & $9.3 \pm 1.7$ & 0.913 \\
\hline $\operatorname{Max} E_{2}, \mathrm{pg} / \mathrm{ml}$ & $1640 \pm 1205$ & $1916 \pm 1128$ & $1406 \pm 928$ & 0.026 \\
\hline Endometrial thickness on day of ET & $10.4 \pm 1.7$ & $10.4 \pm 1.8$ & $10.7 \pm 1.6$ & 0.490 \\
\hline Oocytes retrieved, $\mathrm{n}$ & $7.4 \pm 4.9$ & $9.2 \pm 5.3$ & $7.6 \pm 4.5$ & 0.087 \\
\hline MII, n & $6.2 \pm 4.2$ & $7.2 \pm 4.7$ & $5.6 \pm 3.7$ & 0.095 \\
\hline Fertilization rate, $\%$ & $69 \pm 42$ & $70 \pm 33$ & $62 \pm 29$ & 0.500 \\
\hline Number of Grade 1-2 embyos, $n$ & $3.2 \pm 2.9$ & $4.4 \pm 3.2$ & $2.9 \pm 2.1$ & $0.014^{\mathrm{a}}$ \\
\hline Number of embryos transferred, $n$ & $1.1 \pm 0.7$ & $1.2 \pm 0.6$ & $1.2 \pm 0.5$ & 0.291 \\
\hline Cycle cancellation, n (\%) & $10(\% 17.9)$ & $6(\% 10.2)$ & $4(\% 4.7)$ & 0.039 \\
\hline Pregnancy, n (\%) & $15(\% 26.8)$ & $20(\% 33.9)$ & $31(\% 36.5)$ & 0.141 \\
\hline Clinical pregnancy, n (\%) & $13(\% 23.2)$ & $20(\% 33.9)$ & 26 (\%30.6) & 0.112 \\
\hline Miscarriage, n (\%) & $1(\% 1.8)$ & $2(\% 3.4)$ & $2(\% 2.4)$ & 0.148 \\
\hline Ongoing pregnancy, n (\%) & $12(\% 21.4)$ & $18(\% 30.5)$ & $24(\% 28.2)$ & 0.126 \\
\hline OHSS, n (\%) & 0 & 0 & 0 & \\
\hline
\end{tabular}

\section{CONCLUSION}

In assisted reproductive technology (ART), it is important to seek a balance between optimum ovarian stimulation and good clinical outcome with high pregnancy and minimal moderate/severe OHSS rates.

Our results suggest that $\mathrm{GnRH}$ agonist or dual or hCG triggering have similar outcome in terms of ongoing pregnancy in normoresponder patients. However, dual trigger results in more good quality embryos and GnRH agonist trigger results in more cycle cancellations. Further randomized controlled studies are needed to confirm our findings.

\section{REFERENCES}

and hCG treatment on VEGF, angiopoietin-2, and VE-cadherin: trying to explain the link to ovarian hyperstimulation syndrome. Fertil. Stent. 95, 2517-2519. gonadotropins in patients at risk of the ovarian hyperstimulation syndrome. Gynecor induction of the ovulatory range of Segal, S., Casper, R.F., 1992. Gonadotropin-releasing hormone agonist
triggering follicular maturation in in vitro fertilization. Fertil. Steril. 57, 1254-1258. Ko, S., Lewit, N., Itskovitz-Eldor, J., 1996. Ovarian hyperstimulation syndrome after using gonadotropin-releasing 